\title{
Pattern of extragastric recurrence and the role of abdominal computed tomography in surveillance after endoscopic resection of early gastric cancer: Korean experiences
}

\author{
Sunpyo Lee ${ }^{1}$ - Kee Don Choi ${ }^{1}$ Seung-Mo Hong ${ }^{2} \cdot$ Seong Hwan Park ${ }^{1}$. \\ Eun Jeong Gong ${ }^{1} \cdot$ Hee Kyong $\mathrm{Na}^{1} \cdot$ Ji Yong Ahn ${ }^{1} \cdot$ Kee Wook Jung ${ }^{1}$ • \\ Jeong Hoon Lee ${ }^{1} \cdot$ Do Hoon Kim ${ }^{1} \cdot$ Ho June Song ${ }^{1} \cdot$ Gin Hyug Lee ${ }^{1}$. \\ Hwoon-Yong Jung ${ }^{1} \cdot$ Jin-Ho Kim ${ }^{1}$
}

Received: 26 October 2016/Accepted: 9 January 2017/Published online: 27 January 2017

(c) The International Gastric Cancer Association and The Japanese Gastric Cancer Association 2017

\begin{abstract}
Background Although extragastric recurrence after endoscopic resection of early gastric cancer is rare, it is important because of its potentially fatal outcomes. We investigated the patterns of extragastric recurrence after endoscopic resection and evaluated the role of abdominal computed tomography in surveillance.

Methods Between July 1994 and June 2014, 4915 patients underwent endoscopic resection of early gastric cancer. Because of follow-up periods of less than 6 months and consecutive surgery within 1 year, 810 patients were excluded. Thus, 4105 patients were retrospectively reviewed.

Results The median follow-up period was 37 months (interquartile range 20-59.6 months). The overall incidence of extragastric recurrence was $0.37 \%(n=15)$. In patients who underwent curative resection, the incidence was $0.14 \%(n=5)$. There were three recurrences in the absolute indication group, six in the expanded indication group, and six in the beyond expanded indication group. The median time to extragastric recurrence was 17 months (interquartile range 16.5-43.2 months). Of the 15 extragastric recurrences, 11 were in the regional lymph nodes and 4 were in the liver, adrenal gland, and peritoneum. Sixty percent (9/15) of the extragastric recurrences occurred without intragastric lesions. Eleven recurrences
\end{abstract}

Kee Don Choi

keedonchoi@gmail.com

1 Department of Gastroenterology, Asan Medical Center, University of Ulsan College of Medicine, 88, Olympicro 43-gil, Songpa-gu, Seoul 05505, Korea

2 Department of Pathology, Asan Medical Center, University of Ulsan College of Medicine, Seoul, Korea were detected by abdominal computed tomography, and eight patients underwent curative surgery.

Conclusions After endoscopic resection of early gastric cancer, regional lymph node recurrence is the predominant extragastric recurrence pattern, which can be detected via abdominal computed tomography and cured by rescue surgery. Abdominal computed tomography should be considered as a surveillance method, especially in patients with an expanded indication.

Keywords Early gastric cancer - Endoscopic resection . Extragastric recurrence $\cdot$ Surveillance $\cdot$ Abdominal CT

\section{Introduction}

Early gastric cancer (EGC) is defined as gastric cancer that is confined to the mucosa or submucosa, irrespective of lymph node metastasis [1]. Complete cure can almost always be achieved by conventional gastrectomy with lymph node dissection [2]. Concurrently, endoscopic resection such as endoscopic submucosal dissection (ESD) is also accepted as a standard treatment for EGC with a negligible risk of lymph node metastasis because it is minimally invasive and safe and provides good postoperative quality of life [2-4]. A number of studies have reported a favorable prognosis after curative resection of EGC by endoscopic resection [5-8]. Although the 5-year overall survival and 5-year disease-specific survival rates of patients with EGC after curative therapy are more than $97 \%$ and $99 \%$ respectively [7-9], there have been several reports of EGC recurrence after curative treatment, which can lead to unfavorable outcomes $[8,10,11]$. After curative endoscopic resection, the recurrence rate ranges from $4.5 \%$ to $16 \%$. The commonest recurrence pattern is 
metachronous recurrence in the remnant stomach, followed by local recurrence at the primary resection site and, rarely, extragastric recurrence $[6,7,9,12]$. After curative resection, the 2010 Japanese gastric cancer treatment guidelines recommend follow-up with annual or biannual endoscopy for tumors of absolute and expanded indications, and abdominal ultrasonography or computed tomography (CT) scans for tumors of expanded indication [2]. Scheduled endoscopic surveillance effectively detects almost all intragastric recurrences, which can again be treated with endoscopic resection [13-15]. However, the role of CT in surveillance after endoscopic resection is unclear. In the present study, we investigated the incidence and clinical course of extragastric recurrence of EGC after endoscopic resection and evaluated the role of abdominal CT as a surveillance method.

\section{Patients and methods}

\section{Patients}

All patients in whom EGC was diagnosed after treatment with endoscopic resection, including endoscopic mucosal resection and ESD, between January 1994 and June 2014 in the Department of Gastroenterology, Asan Medical Center, were retrospectively enrolled and analyzed. Patients were excluded from the study if any of the following criteria applied: (1) the follow-up period was less than 6 months; (2) they underwent consecutive gastrectomy and lymph node dissection within 1 year because of noncurative resection, synchronous EGC, or the physician's recommendation; (3) there was no adenocarcinoma in the resected specimen; or (4) the indication and curability of the specimen was not evaluable (Fig. 1). In patients with multiple EGCs, the most advanced lesion was considered in the analysis.

\section{Definitions}

Curative resection for EGCs with an absolute indication was to be performed when all of the following conditions were achieved: en bloc resection; negative horizontal and vertical margins; no lymphovascular invasion; and differentiated intramucosal tumor of $2 \mathrm{~cm}$ or smaller without ulcerative findings. Curative resection for an expanded indication was classified into four discrete groups, which included the following: category I (differentiated intramucosal tumor larger than $2 \mathrm{~cm}$ without ulcerative findingsI); category II (differentiated intramucosal tumor of $3 \mathrm{~cm}$ or smaller with ulcerative findings); category III (undifferentiated intramucosal tumor of $2 \mathrm{~cm}$ or smaller without ulcerative findings); and category IV (differentiated tumor of $3 \mathrm{~cm}$ or smaller with submucosal invasion of less than $500 \mu \mathrm{m})$. These expanded indication patients also needed to fulfill the requirements for en bloc resection, negative horizontal and vertical margins, and no lymphovascular invasion [2].

The endoscopic procedures of our institution have been described previously [5]. Briefly, they are as follows: use of dots to mark the outside of the lesion; the injection of saline solution containing epinephrine and indigo carmine into the submucosal layer; and removal of the lesion with a snare in endoscopic mucosal resection, or a circumferential incision into the mucosa and submucosal dissection with various electronic knives in ESD.

\section{Histological examination}

For histological examination, the resected specimen was stretched, pinned to a polystyrene plate, and totally immersed in $10 \%$ neutral buffered formalin. After fixation, the specimen was grossly examined to identify the lesion and closest resection margin. After application of black ink to all lateral and deep resection margins, the entire specimen was sectioned into 2-mm-thick slices parallel to an imaginary line drawn from the edge of the tumor to the closest resection margin. Each sliced tissue specimen was then embedded in paraffin, and $5-\mu \mathrm{m}$ sections were cut from each paraffin block and stained with hematoxylin and eosin. All of the lesions were classified as a gastrointestinal epithelial neoplasia in accordance with the Vienna classification (i.e. low-grade adenoma/dysplasia for category 3 lesions, high-grade adenoma/dysplasia or noninvasive carcinoma for category 4 lesions, and intramucosal carcinoma or submucosal carcinoma or beyond for category 5 lesions [16]. The histological type of the tumors was classified with the World Health Organization classification of tumors [17]. Lymphovascular invasion was defined as the observable spread of tumor cells through the lymphatic vessels (e.g., carcinoma cells floating within the endothelia-lined space).

\section{Follow-up after endoscopic resection}

Patients were followed up with an endoscopic examination and abdominal CT. Both procedures were performed every 6 months for the first 2 years and then annually for the next 3 years. Extragastric recurrence was defined as regional recurrence in perigastric lymph nodes and distant recurrence in the liver, lung, bone, brain, distant lymph nodes, and peritoneum, irrespective of intragastric lesions. Recurrence in the extragastric field was detected by abdominal CT and confirmed with tissue taken by ultrasonography-guided or endoscopic-ultrasonography-guided 


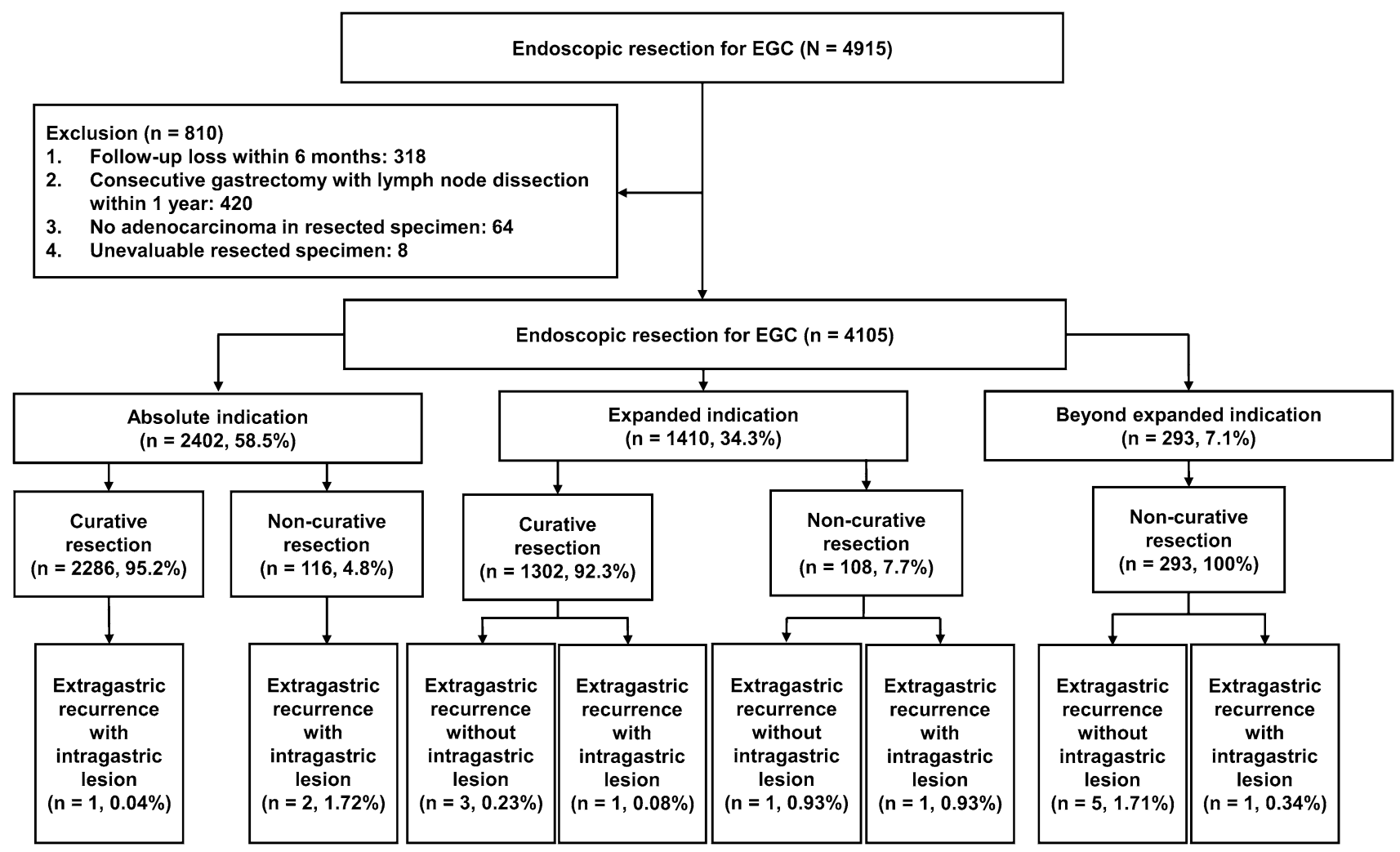

Fig. 1 Flowchart for the enrolled patients who underwent endoscopic resection for early gastric cancer (EGC): incidence and pattern of extragastric recurrence

biopsy or rescue surgery. In some cases, recurrence was presumed on the basis of CT findings.

Overall survival was estimated by the Kaplan-Meier method and compared with the log-rank test. This analysis was performed with the statistical software package IBM SPSS for Windows (version 21.0; IBM, Armonk, NY, USA). This study was approved by the Institutional Review Board of Asan Medical Center (2015-1073). Before endoscopic resection, all patients provided oral and written informed consent for the procedure.

\section{Results}

\section{Study patients}

Between July 1994 and June 2014, 4915 EGC patients underwent endoscopic resection of their tumor at Asan Medical Center. On the basis of our exclusion criteria, 810 patients were excluded from the study. Thus, 4105 patients were analyzed. The median follow-up period for all study patients was 37 months (interquartile range 20-59.6 months). With use of the indication criteria for endoscopic resection, the patients were divided into three groups: 2402 patients $(58.5 \%)$ in the absolute indication group, 1410 patients $(34.3 \%)$ in the expanded indication group, and 293 patients (7.1\%) in the beyond expanded indication group (Fig. 1).

\section{Treatment outcomes of endoscopic resection in accordance with the indication criteria}

Overall, curative resection was achieved in 3588 patients (87.4\%): 2286 patients $(95.2 \%)$ in the absolute indication group and 1302 patients $(92.3 \%)$ in the expanded indication group (Fig. 1). In the subgroup analysis of the expanded indication group based on the four indication categories of the Japanese gastric cancer treatment guidelines, primary EGCs were classified as follows: category I (differentiated intramucosal tumor larger than $2 \mathrm{~cm}$ without ulcers), 1025 patients $(72.8 \%)$; category II (differentiated intramucosal tumor of $3 \mathrm{~cm}$ or smaller with ulcers), 99 patients $(7 \%)$; category III (undifferentiated intramucosal tumor of $2 \mathrm{~cm}$ or smaller without ulcers), 128 patients $(9.1 \%)$; and category IV (differentiated tumor of $3 \mathrm{~cm}$ or smaller with submucosal invasion less than $500 \mu \mathrm{m}$ without ulcers), 158 patients $(11.1 \%)$. The curative resection rates were $91.7 \%$ in category I, $98 \%$ in category II, $96.9 \%$ in category III, and $88.6 \%$ in category IV.

The overall extragastric recurrence rate after endoscopic resection of EGC was $0.37 \%(n=15)$ (Table 1). When the analysis was confined to patients in which 


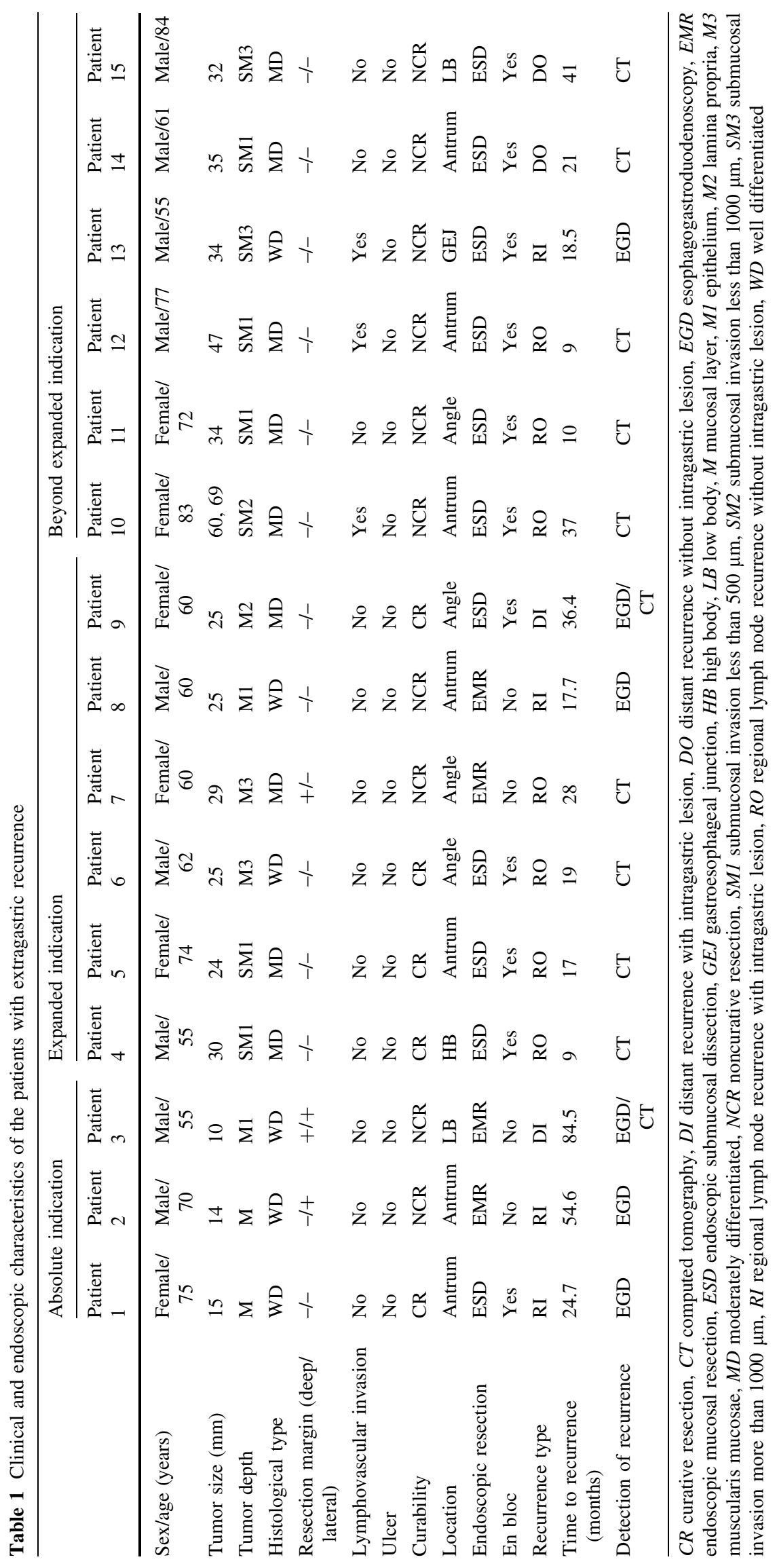


Table 2 Extragastric recurrence patterns and detection methods according to the recurrence pattern after endoscopic resection of early gastric cancer

\begin{tabular}{llllll}
\hline Detection methods & \multicolumn{2}{l}{ Pattern of recurrence } & & \\
\cline { 2 - 3 } \cline { 5 - 6 } & \multicolumn{2}{l}{ Regional LN recurrence $(n=11)$} & & Distant recurrence $(n=4)$ \\
\cline { 2 - 3 } \cline { 5 - 6 } & Without intragastric lesion & With intragastric lesion & & Without intragastric lesion & With intragastric lesion \\
\hline EGD alone & 0 & $4(26.7 \%)$ & 0 & 0 \\
CT alone & $7(46.7 \%)$ & 0 & $2(13.3 \%)$ & 0 \\
Both EGD and CT & 0 & 0 & 0 & $2(13.3 \%)$ \\
\hline
\end{tabular}

$C T$ computed tomography, EGD esophagogastroduodenoscopy, $L N$ lymph node

curative resection was achieved, the extragastric recurrence rate was $0.14 \%(n=5)$. In the absolute indication group, three extragastric recurrences $(0.12 \%)$ were detected: one $(0.04 \%)$ after curative resection and two $(1.72 \%)$ after noncurative resection. In the expanded indication group, six extragastric recurrences $(0.43 \%)$ were detected: four $(0.31 \%)$ after curative resection and two $(1.85 \%)$ after noncurative resection. Four noncurative resections across both indication groups were due to a failure of en bloc resection. Among them, one patient in the absolute indication group had a positive lateral resection margin but, in the first follow-up endoscopy, the biopsy from the endoscopic resection site showed no remnant malignant cells. All of these patients were followed up closely without additional surgery. The other six recurrences were detected in patients in the beyond expanded indication group $(2.05 \%)$. Additional surgery was recommended to these patients, but some of them chose surveillance instead of additional surgery. The median time to extragastric recurrence after endoscopic resection was 17 months (interquartile range 16.5-41.2 months; Fig. 1).

Overall, death from any cause occurred in 312 patients (7.9\%): 170 deaths $(7.1 \%)$ in the absolute indication group, 107 deaths $(7.6 \%)$ in the expanded indication group, and 35 deaths $(11.9 \%)$ in the beyond expanded indication group. Death related to gastric cancer occurred in eight patients overall $(0.2 \%)$ : two deaths in the absolute indication group $(0.08 \%)$, one death in the expanded indication group $(0.07 \%)$, and five deaths in the beyond expanded indication group (1.71\%). All of these patients died because of gastric cancer progression after extragastric recurrence with or without intragastric recurrence (Table 2). The 5-year overall survival rate was $94 \%$, and the 5-year disease-specific survival rate was $99.6 \%$. When subdivided according to indication, the 5-year overall survival rates were $95.2 \%$ in the absolute indication group, $93.5 \%$ in the expanded indication group, and $85.8 \%$ in the beyond expanded indication group (Fig. 2).

\section{Clinical and endoscopic characteristics of the patients with extragastric recurrence}

The clinical and endoscopic characteristics of the patients with extragastric recurrence are presented in Table 1 . The time to recurrence from endoscopic resection ranged from 9 to 84.5 months. All primary lesions had a differentiated histological type. In more than half of the patients, the tumor invaded the submucosal layer, and one fifth showed lymphovascular invasion. Of the 15 extragastric recurrences, 11 were in the regional lymph nodes and 4 were in the liver, adrenal gland, and peritoneum. In the absolute indication group, all extragastric recurrences were accompanied by metachronous intragastric lesions and were initially detected via endoscopy. In the expanded indication group, four of the six extragastric recurrences developed in the regional lymph nodes and the adrenal gland without intragastric lesions and could be detected only by abdominal CT. Two extragastric recurrences with intragastric lesions were found by endoscopy. In the beyond expanded indication group, five of the six extragastric recurrences did not have concurrent intragastric lesions and consisted of three regional lymph node recurrences and two distant recurrences, which were found by abdominal CT (Table 2).

\section{Treatment outcomes in the patients with extragastric recurrence}

Six patients who had regional lymph node recurrences with or without intragastric lesions in the absolute and expanded indication groups were treated with curative surgery. In the absolute indication group, one patient, who had metachronous advanced gastric cancer with regional lymph node metastasis and underwent rescue surgery with postoperative chemotherapy, died of secondary mesenteric recurrence encasing the superior mesenteric artery. In the expanded indication group, one patient with regional lymph node recurrence without an intragastric lesion refused rescue surgery and started chemotherapy. After three cycles of chemotherapy, he refused further treatment 


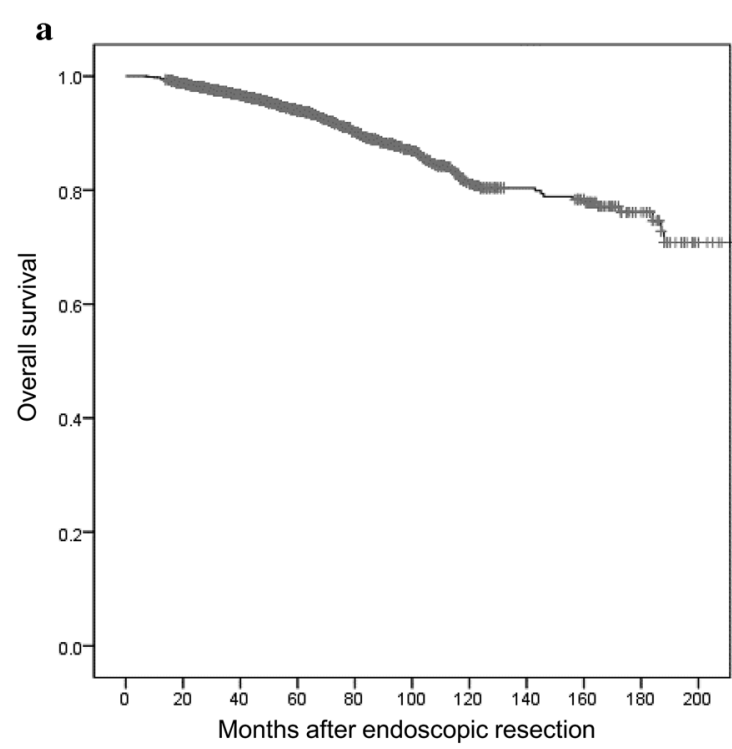

Fig. 2 Kaplan-Meier survival curves for overall survival of early gastric cancer (EGC) patients after endoscopic resection: a overall survival of all EGC patients treated with endoscopic resection;

because of chemotherapy intolerance. At 68 months after recurrence, the number of regional lymph nodes with recurrent tumors was increasing. In the beyond expanded indication group, one patient with regional recurrence without an intragastric lesion 37 months after endoscopic resection underwent curative surgery and was alive 19 months after the recurrence. All patients with extragastric recurrence involving distant organs across each indication group, irrespective of intragastric lesions, died of gastric cancer progression. Two patients with regional lymph node recurrence with intragastric lesions as advanced gastric cancer died of another recurrence even after curative surgery and adjuvant chemotherapy (Table 3).

\section{Discussion}

Endoscopic resection for the treatment of EGC has been performed for more than 20 years. With the accumulation of experience and technical advances, its indication has widened. From the early days of endoscopic resection for treatment of EGC, lymph node metastasis has been a concern; however, several large studies determined that curative resection of EGC meeting the absolute and expanded indications carries a negligible risk of lymph node metastasis $[4,5,18]$. Extragastric recurrence has been reported as a rare experience or in small case series from several large centers. In the present study, although more than 4000 patients received a diagnosis of EGC and underwent endoscopic resection, extragastric recurrence b

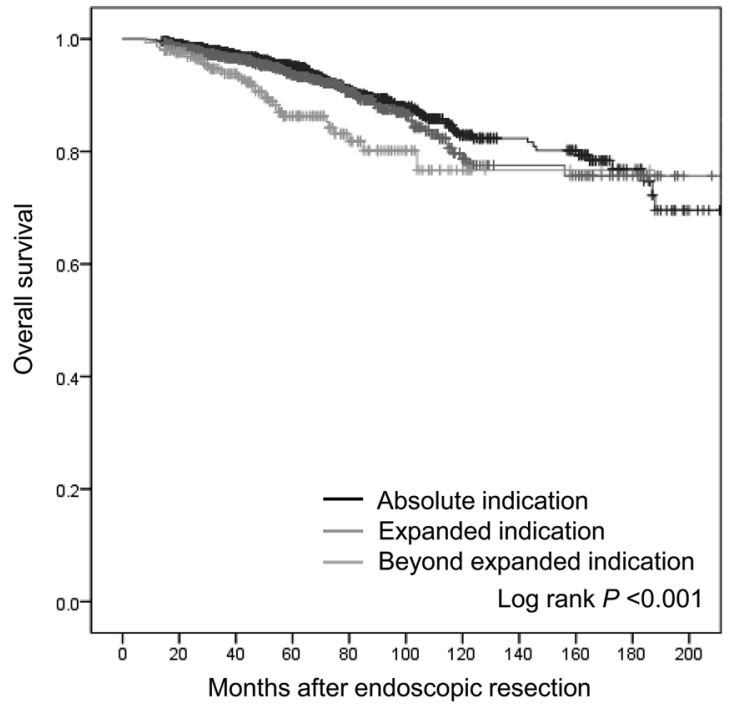

b overall survival of EGC patients treated with endoscopic resection according to the indication

occurred in 15 patients $(0.37 \%)$ and in just 5 patients who underwent curative resection $(0.14 \%)$. A previous Korean study by Min et al. [8] reported two extragastric recurrences among 1306 patients in the absolute and expanded indication groups who underwent curative endoscopic resection $(0.15 \%)$. In large-scale studies from Japan, similar results have been found. Oda et al. [19] detected three cases of extragastric recurrence in 2999 patients from six institutions who underwent curative endoscopic resection for primary EGC meeting the absolute and expanded indications $(0.1 \%)$. More recently, Suzuki et al. [9] reported two cases of extragastric recurrence in 1537 patients $(0.13 \%)$ who underwent curative ESD for EGCs that met the absolute and expanded indications and had a median follow-up period of 83.3 months. Consistent with the findings from these large-scale studies from both Korea and Japan, our current study confirmed the rarity of extragastric recurrence after curative endoscopic resection of EGCs meeting expanded indications.

Regional lymph node recurrence is the predominant pattern of extragastric recurrence after endoscopic resection. In the present study, of the 15 extragastric recurrences, 11 were in the regional lymph nodes and 4 were in the liver, adrenal gland, and peritoneum. A recent study from Korea [8] analyzing extragastric recurrence after curative endoscopic resection reported eight extragastric recurrences in a single center and from a literature review; seven of these were regional lymph node recurrences, as in the present study. In the previously mentioned Japanese studies [9, 19], three cases among five extragastric recurrences were regional lymph node recurrence and two cases 
Table 3 Treatment outcomes among the study patients with extragastric recurrence

\begin{tabular}{|c|c|c|c|c|c|}
\hline Patient & Indication & Curability & Recurrence type & $\begin{array}{l}\text { Treatment for } \\
\text { recurrence }\end{array}$ & Outcome \\
\hline 1 & Absolute & $\mathrm{CR}$ & Regional LN recurrence with metachronous AGC & STG & $\begin{array}{l}\text { Dead } \\
\quad(56.2 \text { months })\end{array}$ \\
\hline 2 & Absolute & NCR & Regional LN recurrence with metachronous EGC & STG & $\begin{array}{l}\text { Alive } \\
\text { (108.7 months) }\end{array}$ \\
\hline 3 & Absolute & NCR & Distant recurrence with metachronous EGC (liver, lung) & Refusal & $\begin{array}{l}\text { Dead } \\
\quad(3.6 \text { months })\end{array}$ \\
\hline 4 & Expanded & $\mathrm{CR}$ & Regional LN recurrence & $\mathrm{TG}+\mathrm{CTx}$ & $\begin{array}{l}\text { Alive } \\
\text { (34 months) }\end{array}$ \\
\hline 5 & Expanded & $\mathrm{CR}$ & Regional LN recurrence & $\mathrm{TG}+\mathrm{CTx}$ & $\begin{array}{l}\text { Alive } \\
\text { (79 months) }\end{array}$ \\
\hline 6 & Expanded & CR & Regional LN recurrence & CTx & $\begin{array}{l}\text { Alive } \\
\text { (68 months) }\end{array}$ \\
\hline 7 & Expanded & NCR & Regional LN recurrence & STG & $\begin{array}{l}\text { Alive } \\
\text { (135 months) }\end{array}$ \\
\hline 8 & Expanded & NCR & Regional LN recurrence with metachronous EGC & STG & $\begin{array}{l}\text { Alive } \\
\text { (164.6 months) }\end{array}$ \\
\hline 9 & Expanded & CR & $\begin{array}{l}\text { Distant and regional LN recurrence with metachronous EGC } \\
\text { (left adrenal gland) }\end{array}$ & CTx & $\begin{array}{l}\text { Dead } \\
\quad(34.8 \text { months })\end{array}$ \\
\hline 10 & $\begin{array}{l}\text { Beyond } \\
\text { expanded }\end{array}$ & NCR & Regional LN recurrence & STG & $\begin{array}{l}\text { Alive } \\
\text { (19 months) }\end{array}$ \\
\hline 11 & $\begin{array}{l}\text { Beyond } \\
\text { expanded }\end{array}$ & NCR & Regional LN recurrence & CTx & $\begin{array}{l}\text { Dead } \\
\text { (33 months) }\end{array}$ \\
\hline 12 & $\begin{array}{l}\text { Beyond } \\
\text { expanded }\end{array}$ & NCR & Regional LN recurrence & Refusal & Dead (9 months) \\
\hline 13 & $\begin{array}{l}\text { Beyond } \\
\text { expanded }\end{array}$ & NCR & Regional LN recurrence with locally recurred AGC & $\mathrm{TG}+\mathrm{CTx}$ & $\begin{array}{l}\text { Dead } \\
\quad(31.7 \text { months })\end{array}$ \\
\hline 14 & $\begin{array}{l}\text { Beyond } \\
\text { expanded }\end{array}$ & NCR & Distant and regional LN recurrence (liver) & CTx & $\begin{array}{l}\text { Dead } \\
\quad(11 \text { months })\end{array}$ \\
\hline 15 & $\begin{array}{l}\text { Beyond } \\
\text { expanded }\end{array}$ & NCR & Distant and regional LN recurrence (peritoneal seeding) & Refusal & Dead (3 months) \\
\hline
\end{tabular}

$A G C$ advanced gastric cancer, $C R$ curative resection, $C T x$ chemotherapy, $E G C$ early gastric cancer, $L N$ lymph node, $N C R$ noncurative resection, $S T G$ subtotal gastrectomy, $T G$ total gastrectomy

were a distant lymph node metastasis with local recurrence. After curative surgery for EGC, in contrast, the commonest recurrence pattern was distant recurrence through hematogenous spread to other organs such as the liver, followed by locoregional recurrence in the regional lymph nodes and anastomotic sites and peritoneal recurrence [20-22]. This difference in the pattern of recurrence requires distinct therapeutic approaches and leads to different outcomes. There is no curative treatment for hematogenous or peritoneal recurrence; therefore, palliative chemotherapy is given in the hope of improving survival. However, gastric cancer tends to progress with unfavorable outcomes. In cases of regional lymph node recurrence, surgical resection with curative intent is possible. In the current study, six patients with regional lymph node recurrences were treated with curative surgery; one in the absolute indication group, four in the expanded indication group, and one in the beyond expanded indication group. When the recurrence is confined to the regional lymph nodes and detected early, with a small number of affected nodes, surgical resection can be an effective and curative treatment. When patients with EGC are left untreated, several studies have reported that approximately $25-64 \%$ of the cancers progress to the advanced stage and half of the patients die of gastric cancer progression within 5 years of diagnosis [23, 24]. The disease course might be similar in cases of extragastric recurrence. For the same T category, more regional lymph nodes being involved leads to a lower 5-year survival rate [25]. If regional lymph node recurrence is detected early with a small number of affected nodes, patients have a higher chance of cure. With a curative operation, a greater than 96\% 5-year survival rate can be achieved in EGC with lymph node metastasis at stages such as T1N1 [25]. Even after noncurative endoscopic resection of EGC, additional radical gastrectomy with lymph node dissection showed a 5-year overall 
survival rate of $94.3-94.7 \%$, which is significantly greater (by about 10 percentage points) than that seen after no treatment [26-28]. For extragastric recurrences involving only regional lymph nodes, some case reports and studies showed good prognosis after curative surgery [8, 19]. Therefore, surveillance for early detection of extragastric recurrence and curative surgery in cases of regional lymph node recurrence should be recommended after endoscopic treatment of EGC.

Although the value of postoperative surveillance remains controversial [29-31], major guidelines recommend regular and systematic follow-up with endoscopy and cross-sectional imaging, and many cancer centers have established their own follow-up protocols after curative treatment that include these methods [2, 32, 33]. The role of endoscopy in surveillance after endoscopic resection has been proven in several studies, but its role is limited to the detection of intragastric recurrence [13-15]. In the present study, all the extragastric recurrences with intragastric lesions were initially detected by endoscopy. However, the role of CT after endoscopic resection is not clear. After surgical resection of gastric cancer, use of abdominal CT has not been shown to improve long-term survival [30, 31, 34]. In colorectal cancer, several randomized clinical trials and meta-analyses have reported that intensive follow-ups that included CT after curative resection increased the rate of curative surgery for recurrence compared with minimal follow-ups [35, 36]. In hepatocellular carcinoma, surveillance with high-quality cross-sectional imaging is also recommended after primary resection. This is because hepatocellular carcinoma tends to recur locally rather than at distant sites; therefore, earlier identification can provide an opportunity for curative treatment that prolongs survival [37, 38]. In EGC, some studies have evaluated the role of $\mathrm{CT}$ in surveillance for intramucosal gastric cancer after curative endoscopic resection, reporting that CT had a minor or nonexistent role in detecting local or metachronous gastric recurrence [13, 15]. However, these reports included only patients with intragastric recurrence and thus could not define the role of abdominal CT in extragastric recurrence. In the current study, followup was performed with endoscopy and abdominal CT, and $73.3 \%(11 / 15)$ of extragastric recurrences were detected via abdominal CT. In the absolute indication group, all extragastric recurrences arose with metachronous intragastric lesions and were initially detected via endoscopy. Therefore, surveillance with esophagogastroduodenoscopy may be enough for this group. In the expanded and the beyond expanded indication groups, $66.7 \%(4 / 6)$ and $83.3 \%(5 / 6)$ of extragastric recurrences were not accompanied by intragastric recurrence and were found only by abdominal CT. With this diagnostic method, it was possible to find extragastric recurrences that did not have intragastric lesions, and patients had an increased chance of survival with additional curative surgery and/or chemotherapy. Nevertheless, the beyond expanded indication group had poorer survival with distant recurrences. Additional surgery after endoscopic resection should be recommended instead of surveillance in the beyond expanded indication group.

PET/CT has been evaluated in a few studies as another surveillance method for gastric cancer patients who have undergone gastrectomy [39, 40]. A large study found that PET/CT could be a useful imaging modality for the followup of gastric cancer patients, particularly advanced gastric cancer patients, but was limited in its ability to detect local and peritoneal metastasis [40]. Also, a recent study compared PET/CT with CT in gastric cancer diagnosis and reported that $\mathrm{PET/CT}$ had diagnostic effectiveness in the identification of regional metastatic nodes but not distant abdominal metastases [41]. However, there have been very few studies on the role of PET/CT as a surveillance method after surgical or endoscopic resection of EGC. In the current study, we did not evaluate the performance of PET/CT in the surveillance of EGC patients after endoscopic resection. Further studies are thus needed in this regard.

A number of studies have reported the outcome of endoscopic resection for EGC. Recent reports from Korea and Japan included large populations of EGC patients and longer follow-up periods [8, 9, 19, 28]. In terms of extragastric recurrence, all of the studies to date have reported a low incidence and a common pattern. In the expanded indication population in which curative resection was achieved, the rate of extragastric recurrence was much lower and the predominant pattern was regional lymph node recurrence that could be resolved with rescue surgery. Thus, surveillance after endoscopic resection was reasonable and appropriate under this condition. However, in the beyond expanded indication population described thus far, endoscopic resection was noncurative and the rate of distant metastasis was higher, leading to a poorer prognosis and requiring additional surgery after endoscopic resection. Unlike previous studies, here we evaluated extragastric recurrence in patients with curative and noncurative resections. Moreover, we examined the correlation between intragastric recurrence and extragastric recurrence, and identified the proportion of patients in our cohort with extragastric recurrence without intragastric recurrence $(60 \%)$. This result emphasizes the important role of CT in the surveillance of gastric cancer patients.

The current study had some noteworthy limitations associated with its retrospective design. First, patients lost to follow-up within 6 months of endoscopic resection were excluded from the analysis of extragastric recurrence. Thus, its incidence might have been underestimated. Second, the median follow-up period may not have been long enough to 
encounter slowly emerging extragastric recurrences, such as those detected more than 5 years after endoscopic resection. Third, our study series included extragastric recurrences accompanied by metachronous EGC or advanced gastric cancer and it was not possible to tell whether these recurrences originated from the primary EGC or the metachronous intragastric lesion. However, because we aimed to analyze all possible extragastric recurrences, we included these types of extragastric recurrence, making the analysis more comprehensive. Notwithstanding these limitations, our study also had several strengths. First, it included the largest population of patients with EGC reported to date. Second, the rate of standardized follow-up was high $(92.8 \%$, 4105/4423). Third, the endoscopic procedure and reports of pathologic findings were performed in accordance with a standardized format.

Our current large-scale retrospective cohort study showed the rarity of extragastric recurrence after endoscopic resection of EGC as well as the feasibility of endoscopic resection of EGC meeting the absolute and expanded indications. Regional lymph node recurrence was confirmed as the predominant type of extragastric recurrence. In the absolute indication group, as extragastric recurrences occurred with metachronous intragastric recurrences, abdominal CT had a limited role in detecting recurrences. In the expanded indication group, however, as the proportion of patients with extragastric recurrence without intragastric recurrence was higher than that with intragastric lesions, abdominal CT performed well in the detection of recurrence. Furthermore, patients with regional lymph node recurrences could potentially be cured by rescue surgery. Therefore, the value of abdominal CT should be emphasized as an important part of the surveillance strategy after endoscopic resection of EGC that meets the expanded indication criteria.

\section{Compliance with ethical standards}

Conflict of interest The authors declare that they have no conflict of interest.

Human rights statement and informed consent All procedures followed were in accordance with the ethical standards of the Institutional Review Board of Asan Medical Center and with the Helsinki Declaration of 1964 and later versions. Informed consent was obtained from all patients for their being included in the study.

Funding This work was not supported by any direct or indirect funding.

\section{References}

1. Japanese Gastric Cancer Association. Japanese classification of gastric carcinoma: 3rd English edition. Gastric Cancer. 2011;14:101-12.
2. Japanese Gastric Cancer Association. Japanese gastric cancer treatment guidelines 2010 (ver. 3). Gastric Cancer. 2011;14:113-23.

3. Gotoda T, Iwasaki M, Kusano C, Seewald S, Oda I. Endoscopic resection of early gastric cancer treated by guideline and expanded National Cancer Centre criteria. $\mathrm{Br} \mathrm{J}$ Surg. 2010;97:868-71.

4. Isomoto H, Shikuwa S, Yamaguchi N, Fukuda E, Ikeda K, Nishiyama H, et al. Endoscopic submucosal dissection for early gastric cancer: a large-scale feasibility study. Gut. 2009;58:331-6.

5. Ahn JY, Jung HY, Choi KD, Choi JY, Kim MY, Lee JH, et al. Endoscopic and oncologic outcomes after endoscopic resection for early gastric cancer: 1370 cases of absolute and extended indications. Gastrointest Endosc. 2011;74:485-93.

6. Choi IJ, Lee JH, Kim YI, Kim CG, Cho SJ, Lee JY, et al. Longterm outcome comparison of endoscopic resection and surgery in early gastric cancer meeting the absolute indication for endoscopic resection. Gastrointest Endosc. 2015;81:333-41.e1.

7. Kim YI, Kim YW, Choi IJ, Kim CG, Lee JY, Cho SJ, et al. Longterm survival after endoscopic resection versus surgery in early gastric cancers. Endoscopy. 2015;47:293-301.

8. Min BH, Kim ER, Kim KM, Park CK, Lee JH, Rhee PL, et al. Surveillance strategy based on the incidence and patterns of recurrence after curative endoscopic submucosal dissection for early gastric cancer. Endoscopy. 2015;47:784-93.

9. Suzuki H, Oda I, Abe S, Sekiguchi M, Mori G, Nonaka S, et al. High rate of 5-year survival among patients with early gastric cancer undergoing curative endoscopic submucosal dissection. Gastric Cancer. 2016;19:198-205.

10. Oya H, Gotoda T, Kinjo T, Suzuki H, Yoshinaga S, Taniguchi H, et al. A case of lymph node metastasis following a curative endoscopic submucosal dissection of an early gastric cancer. Gastric Cancer. 2012;15:221-5.

11. Namikawa T, Shiga M, Ichikawa K, Kitagawa H, Kobayashi M, Hanazaki K. Metachronous liver and bone metastasis from small early gastric carcinoma without lymph node involvement: a case report. Mol Clin Oncol. 2013;1:249-52.

12. Ahn JY, Jung HY. Long-term outcome of extended endoscopic submucosal dissection for early gastric cancer with differentiated histology. Clin Endosc. 2013;46:463-6.

13. Sohn YJ, Jang JS, Choi SR, Kwon HC, Jung GJ, Kim MC, et al. Early detection of recurrence after endoscopic treatment for early gastric cancer. Scand J Gastroenterol. 2009;44:1109-14.

14. Kato M, Nishida T, Yamamoto K, Hayashi S, Kitamura S, Yabuta $\mathrm{T}$, et al. Scheduled endoscopic surveillance controls secondary cancer after curative endoscopic resection for early gastric cancer: a multicentre retrospective cohort study by Osaka University ESD Study Group. Gut. 2013;62:1425-32.

15. Park CH, Kim EH, Chung H, Park JC, Shin SK, Lee SK, et al. Role of computed tomography scan for the primary surveillance of mucosal gastric cancer after complete resection by endoscopic submucosal dissection. Surg Endosc. 2014;28:1307-13.

16. Schlemper RJ, Riddell RH, Kato Y, Borchard F, Cooper HS, Dawsey SM, et al. The Vienna classification of gastrointestinal epithelial neoplasia. Gut. 2000;47:251-5.

17. Hamilton SR, Aaltonen LA. Pathology and genetics of tumours of the digestive system. Lyon: IARC Press; 2000.

18. Gotoda T, Sasako M, Ono H, Katai H, Sano T, Shimoda T. Evaluation of the necessity for gastrectomy with lymph node dissection for patients with submucosal invasive gastric cancer. Br J Surg. 2001;88:444-9.

19. Oda I, Oyama T, Abe S, Ohnita K, Kosaka T, Hirasawa K, et al. Preliminary results of multicenter questionnaire study on longterm outcomes of curative endoscopic submucosal dissection for early gastric cancer. Dig Endosc. 2014;26:214-9. 
20. Youn HG, An JY, Choi MG, Noh JH, Sohn TS, Kim S. Recurrence after curative resection of early gastric cancer. Ann Surg Oncol. 2010;17:448-54.

21. Lai JF, Kim S, Kim K, Li C, Oh SJ, Hyung WJ, et al. Prediction of recurrence of early gastric cancer after curative resection. Ann Surg Oncol. 2009;16:1896-902.

22. Sano T, Sasako M, Kinoshita T, Maruyama K. Recurrence of early gastric cancer: follow-up of 1475 patients and review of the Japanese literature. Cancer. 1993;72:3174-8.

23. Tsukuma H, Oshima A, Narahara H, Morii T. Natural history of early gastric cancer: a non-concurrent, long term, follow-up study. Gut. 2000;47:618-21.

24. Jeong SH, Park MI, Kim HH, Park SJ, Moon W. The natural course of early gastric cancer. Korean J Gastroenterol. 2012;60:224-8.

25. Lee HJ, Kim YH, Kim WH, Lee KU, Choe KJ, Kim JP, et al. Clinicopathological analysis for recurrence of early gastric cancer. Jpn J Clin Oncol. 2003;33:209-14.

26. Kim ER, Lee H, Min BH, Lee JH, Rhee PL, Kim JJ, et al. Effect of rescue surgery after non-curative endoscopic resection of early gastric cancer. Br J Surg. 2015;102:1394-401.

27. Oda I, Gotoda T, Sasako M, Sano T, Katai H, Fukagawa T, et al. Treatment strategy after non-curative endoscopic resection of early gastric cancer. Br J Surg. 2008;95:1495-500.

28. Suzuki H, Oda I, Abe S, Sekiguchi M, Nonaka S, Yoshinaga S, et al. Clinical outcomes of early gastric cancer patients after noncurative endoscopic submucosal dissection in a large consecutive patient series. Gastric Cancer. 2016. doi:10.1007/ s10120-016-0651-z.

29. Kim JH, Jang YJ, Park SS, Park SH, Mok YJ. Benefit of postoperative surveillance for recurrence after curative resection for gastric cancer. J Gastrointest Surg. 2010;14:969-76.

30. Kodera Y, Ito S, Yamamura Y, Mochizuki Y, Fujiwara M, Hibi $\mathrm{K}$, et al. Follow-up surveillance for recurrence after curative gastric cancer surgery lacks survival benefit. Ann Surg Oncol. 2003;10:898-902.

31. Bennett JJ, Gonen M, D'Angelica M, Jaques DP, Brennan MF, Coit DG. Is detection of asymptomatic recurrence after curative resection associated with improved survival in patients with gastric cancer? J Am Coll Surg. 2005;201:503-10.

32. Ajani JA, Bentrem DJ, Besh S, D'Amico TA, Das P, Denlinger C, et al. Gastric cancer, version 2.2013. J Natl Compr Canc Netw. 2013;11:531-46.

33. Waddell T, Verheij M, Allum W, Cunningham D, Cervantes A, Arnold D. Gastric cancer: ESMO-ESSO-ESTRO clinical practice guidelines for diagnosis, treatment and follow-up. Eur J Surg Oncol. 2014;40:584-91.

34. D'Ugo D, Biondi A, Tufo A, Persiani R. Follow-up: the evidence. Dig Surg. 2013;30:159-68.

35. Desch CE, Benson AB 3rd, Somerfield MR, Flynn PJ, Krause C, Loprinzi CL, et al. Colorectal cancer surveillance: 2005 update of an American Society of Clinical Oncology practice guideline. J Clin Oncol. 2005;23:8512-9.

36. Primrose JN, Perera R, Gray A, Rose P, Fuller A, Corkhill A, et al. Effect of 3 to 5 years of scheduled CEA and CT follow-up to detect recurrence of colorectal cancer: the FACS randomized clinical trial. JAMA. 2014;311:263-70.

37. Benson AB 3rd, Abrams TA, Ben-Josef E, Bloomston PM, Botha $\mathrm{JF}$, Clary BM, et al. NCCN clinical practice guidelines in oncology: hepatobiliary cancers. J Natl Compr Canc Netw. 2009;7:350-91.

38. Hatzaras I, Bischof DA, Fahy B, Cosgrove D, Pawlik TM. Treatment options and surveillance strategies after therapy for hepatocellular carcinoma. Ann Surg Oncol. 2014;21:758-66.

39. Lee DY, Lee CH, Seo MJ, Lee SH, Ryu JS, Lee JJ. Performance of ${ }^{18} \mathrm{~F}$-FDG $\mathrm{PET} / \mathrm{CT}$ as a postoperative surveillance imaging modality for asymptomatic advanced gastric cancer patients. Ann Nucl Med. 2014;28:789-95.

40. Lee JW, Lee SM, Son MW, Lee MS. Diagnostic performance of FDG PET/CT for surveillance in asymptomatic gastric cancer patients after curative surgical resection. Eur J Nucl Med Mol Imaging. 2016;43:881-8.

41. Staniuk T, Malkowski B, Srutek E, Szlezak P, Zegarski W. Comparison of FLT-PET/CT and CECT in gastric cancer diagnosis. Abdom Radiol (NY). 2016;41:1349-56. 